\title{
Fabrication and Characterization of Chitosan and Pectin Nanostructured Multilayers
}

\author{
Laura Pastorino, * Svetlana Erokhina, Carmelina Ruggiero, Victor Erokhin, \\ and Paola Petrini
}

\section{Introduction}

In the last few years, nanostructured polyelectrolyte capsules (NPCs), with a wide range of architectures and functionalities, have been developed and proposed for applications in biomedicine as smart drug delivery carriers. ${ }^{[1-3]}$ NPCs can be fabricated by the layer-by-layer (LbL) adsorp-

Prof. L. Pastorino, Dr. S. Erokhina, Prof. C. Ruggiero, Department of Informatics, Bioengineering, Robotics and Systems Engineering, University of Genoa, Via Opera Pia 13, 16145 Genoa, Italy (E-mail: laura.pastorino@unige.it, svetlana.erokhina@gmail.com, carmel@dibris.unige.it)

Dr. S. Erokhina, Prof. V. Erokhin, IFMB, Kazan Federal Univer sity Kremliovskaya str. 18, 420008 Kazan, Russia (E-mail: victor.erokhin@fis.unipr.it)

Prof. V. Erokhin, CNR-IMEM Parco delle Scienze 37/A, 43124 Parma, Italy

Prof. P. Petrini, Laboratorio di Biomateriali, Dipartimento di Chimica, Materiali e Ingegneria Chimica 'G. Natta' Piazza Leonardo da Vinci 32, 20133 Milano, Italy

Prof. P. Petrini, UdR INSTM Milano Politecnico, Politecnico di Milano Piazza Leonardo da Vinci 32, 20133 Milano, Italy

Correspondence to: Prof. L. Pastorino (E-mail: laura.pastorino@unige.it) 
tion of oppositely charged polyelectrolytes on the surface of micro/nanoscale sacrificial templates, usually carbonate particles. ${ }^{[4,5]}$ Once the polyelectrolyte multilayer, constituting the capsules shell, has been deposited, the template is removed by dissolution in acidic medium or by chelating agents. It is possible to fabricate hollow polyelectrolyte capsules having a shell with thickness ranging from few to tens of nanometers and predetermined composition, structure and thus functionality. One interesting property of such systems is the possibility to vary their shell permeability as a consequence of specific stimuli, such as $\mathrm{pH}$, in order to load and, when required, release cargo molecules, such as drugs. ${ }^{[6-11]}$ For a wide range of biomedical applications, the use of biocompatible, biodegradable, and low immunogenic systems is of pivotal importance.

In this respect, polysaccharides are interesting building blocks for the development of natural polyelectrolyte capsules. Polysaccharides are a wide class of polymeric materials of natural origin, which exhibit high biocompatibility, biodegradability, bioactivity, processability, and low cost making them very promising natural biomaterials. ${ }^{[12-14]}$ Depending on the natural source, they can have a linear or branched architecture with a wide range of structural characteristics, e.g., molecular weights, types of monosaccharides either their distribution along the backbone or localized in branched regions. This variability is often regarded as a limit, since it affects the reproducibility of the raw materials and produces results depending on the variable characteristics of their structures. However, the main features affecting the final product and process can be fully characterized and controlled. On the other hand, the variability of the characteristics of these materials holds great promise for tailoring the final characteristics of the prospective products.

A few polysaccharides have the advantage of being able to adhere to mucosal surfaces. Mucoadhesion can be experimentally estimated studying their interaction with the protein mucin. ${ }^{[15]}$ Mucins are glycoproteins, which represent the main component of the protective epithelial mucus layer, which acts both as antiadhesive barrier and as mediators between an organ and the external environment. ${ }^{[16]}$ A strong interaction between mucin and a polymer results in a prolonged residence time, which plays a pivotal role in local applications of drugs to specific sites such as the eye, the gastrointestinal track, and the oral and nasal cavity. This can be regarded as a key point in the development of pharmacelutical formulations which can be orally delivered as an alternative to intramuscular delivery by injections. ${ }^{[17]}$ This feature can be of great benefit for the delivery of drugs for chronic disease treatments, reducing the patient discomfort and side effects. ${ }^{[18]}$ We investigated the fabrication of NPCs made of natural polysaccharides. Specifically, we focused on cationic chitosan and anionic pectin. Chitosan, a copolymer of glucosamine and $\mathrm{N}$-acetyl glucosamine, is a polycationic, biocompatible and biodegradable natural biopolymer. Chitosans can be obtained with different amount of amino-groups, which can turn charged depending on the $\mathrm{pH}$, by deacetylation of chitin. Because of their properties, chitosans have great potential in biomedical applications, including drug delivery, tissue engineering and biosensors. ${ }^{[19,20]}$ Pectins, the major structural polysaccharides of higher plant cells, are commercially extracted from citrus peels and apple pomace. ${ }^{[21]}$ Pectins are divided into two major groups on the basis of their degree of esterification (DE), high methoxyl (HM) pectins, and low methoxyl (LM) ones. The degree of methoxylation is related to the anionic charge of pectins. LM pectins has been recently used for different biomedical applications. ${ }^{[22,23]}$ They can be ionically crosslinked by different cations in physiological conditions. The mechanism of the formation of the gels can be controlled in terms of crosslinking degree and kinetic of crosslinking. ${ }^{[2]}$ The use of poorly soluble salt, e.g., $\mathrm{CaCO}_{3}$, led to the formation of homogenous tunable gels. ${ }^{[25]}$ Both chitosans and pectins have been found to possess mucoadhesive properties at the macroscopic level. ${ }^{[26]}$ To our knowledge, this is the first work reporting on the characterization of chitosan and pectin assembling into nanoscale multilayers in order to synthetize NPCs. Since NPCs made of weak polyelectrolytes, such as polysaccharides, the interactions in the multilayer shell are strongly dependent on $\mathrm{pH}$, the shell assembly was characterized at different $\mathrm{pH}$ values, namely $\mathrm{pH} 4,5$, and 6 . The characterization was carried out by real-time dissipative quartz crystal microbalance. ${ }^{[27]}$ The mucoadhesive properties of the proposed composite system were characterized at the nanoscopic level by studying the interaction of the multilayers with the mucoadhesive protein mucin at oral $\mathrm{pH}$ (6.8) and at gastric $\mathrm{pH}$ (1.5) by dissipative quartz crystal microbalance.

The LbL deposition processes are normally performed at $\mathrm{pH}$ values that guarantee that the components are oppositely charged. For this reason we selected $\mathrm{pH} 4-6$ for the assembly. ${ }^{[28]}$ However, the behavior of such structures should be characterized taking into account the $\mathrm{pH}$ of the environment where the structure is going to be used, in this case oral and gastrointestinal pHs. ${ }^{[14,29-31]}$

The optimized assembly protocol was then used for the assembly of the multilayer onto the surface of sacrificial templates, namely $\mathrm{MnCO}_{3}$ and $\mathrm{CaCO}_{3}$. 


\section{Experimental Section}

\subsection{Materials}

Chitosan (CHI, medium molecular weight, 448877, lot MKBD4275V, from Pandalus Borealis, 77\% deacetylation, viscosity $450 \mathrm{mPas}$ at $1 \%$ concentration in $1 \%$ acetic acid) and high methoxyl pectin $\left(\mathrm{PEC}_{\mathrm{HM}}, 76282\right.$, lot $\mathrm{BCBD} 2242 \mathrm{~V}$, from apple) and mucin (from bovine submaxillary glands, type I-S M3895) were purchased from Sigma-Aldrich. Low methoxyl pectin ( $\mathrm{PEC}_{\mathrm{LM}}$, CU701, lot 968, from citrus fruits) was kindly provided by Herbstreith \& Fox (Neuemberg, Germany). Calcium chloride $\left(\mathrm{CaCl}_{2}\right)$, sodium hydroxide $(\mathrm{NaOH})$, acetic acid, and chloridic acid were purchased from Sigma-Aldrich. Calcium and manganesium carbonate $\left(\mathrm{CaCO}_{3}, \mathrm{MnCO}_{3}\right)$ microparticles with a diameter $5 \pm 2$ $\mu \mathrm{m}$ were kindly provided by PlasmaChem Gmb. Sodium azide $\left(\mathrm{NaN}_{3}\right.$ 0.02\% w/v from Sigma-Aldrich) was added to water to guarantee sample sterility during laboratory storage at $4{ }^{\circ} \mathrm{C}$ for up to six months. Water, used in the experiments for the solutions preparation and washing, was purified by Milli-O system and had the resistance of $18.2 \mathrm{M} \Omega \mathrm{cm}$.

\subsection{Characterization of Pectins and Chitosan}

\subsubsection{Moisture Content}

Moisture content was estimated by loss on drying at 50 $\pm 2{ }^{\circ} \mathrm{C}$ under reduced pressure (100 mbar) until constant weight of $1 \mathrm{~g}$ of polysaccharide powder. The test was carried out in triplicate and results expressed as mean \pm standard deviation.

\subsubsection{Size Exclusion Chromatography}

For pectin molecular weight analysis, size exclusion chromatography was employed with aqueous $0.1 \mathrm{M} \mathrm{NaNO}_{3}$ solution as eluent. The analysis was performed at $25^{\circ} \mathrm{C}$

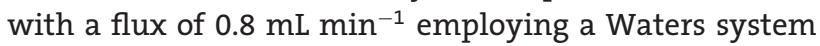
(Waters 1515 pump) equipped with a precolumn (Ultrahydrogel Guard, $60 \times 40 \mathrm{~mm}$ ), three Ultrahydrogel columns (Ultrahydrogel 250, 500, 1000; $7.8 \times 300 \mathrm{~mm}$ ) and a refractive index detector (Waters 2414). The column set was calibrated with pullulan standards (Shodex Showa Denko pullulan standards, range $708-5.9 \mathrm{KDa}$ ) and, therefore, all molecular weight values quoted are relative to these.

\subsubsection{Intrinsic Viscosity}

The intrinsic viscosity of pectins was measured using an Ostwald viscometer. The measurements were made at a temperature of $24 \pm 1^{\circ} \mathrm{C}$. Each polysaccharide $(100 \mathrm{mg})$ was dissolved in $50 \mathrm{~mL}$ of $0.1 \mathrm{M} \mathrm{NaCl}$ solution at room temperature. The measure of the efflux time of the solution was repeated for five times at decreasing concentrations, ob- tained by successive dilution of the solution with aliquots of $5 \mathrm{~mL}$ solvent.

Reduced and inherent viscosity $\left(\eta_{\text {rid }}\right.$ and $\eta_{\text {in }}$, respectively) were calculated and plotted versus $C_{\text {sol }}$. The intrinsic viscosity was calculated as intersection of the $\eta_{\text {rid }}$ and $\eta_{\text {in }}$ lines.

$[\eta]=K M_{\mathrm{v}}^{\alpha}$

The viscosimetric molecular weight of pectins $\left(\bar{M}_{\mathrm{v}}\right.$, Table 1) was calculated from the intrinsic viscosity through the Mark-Howkin-Sakurada equation (Equation (1)) where the constants $K$ and $\alpha$ where $9.55 \times 10^{-4}$ and $\alpha$ $=0.73$ for pectins. ${ }^{[32]}$

\subsubsection{Evaluation of the Degree of Esterification}

The degree of esterification (DE) of pectins was evaluated by a colorimetric method. ${ }^{[33]}$ Briefly, ester groups of pectin were reacted with hydroxylamine to form hydroxamic acid at room temperature. The absorbance of the yelloworange colored complexes with ferric ions was measured by UV spectroscopy. UV spectra were acquired with a UV/vis spectrophotometer (6705, Jenway, 190-1100 nm range).

\subsubsection{Dissipative Quartz Crystal Microbalance (QCM-D)}

For the time-dependent control of adsorption and monitoring of the assembly in situ, the OCM method is suitable. The kinetics of the adsorption process can be delineated by the OCM-technique, which is indispensable for establishing proper assembly conditions (e.g., saturation adsorption time). ${ }^{[34-36]}$ Quantitative studies of the interaction between $\mathrm{CHI}$ and $\mathrm{PEC}_{\mathrm{LM}}$ or $\mathrm{PEC}_{\mathrm{HM}}$ at different $\mathrm{pH}$ values and their interactions with mucin at oral and gastrointestinal $\mathrm{pH}$ values were performed using a dissipative OCM (OCM-Z500, KSV Instruments, Finland). OCM-D measures simultaneously the change in frequency $(\Delta F)$ and energy dissipation $(\Delta D)$ of an oscillating quartz crystal in response to adsorption of material to the crystal surface. We used quartz crystals with diameter $1.5 \mathrm{~cm}$ and a fundamental frequency of $5 \mathrm{MHz}$ with gold electrodes, with thickness $100 \mathrm{~nm}$ and roughness $0.9 \pm 0.2 \mathrm{~nm}$ deposited by physical vapor deposition method. OCM-D technique has been described in detail in refs. ${ }^{[37]}$ and ${ }^{[38]}$. Briefly, the quartz crystal can be excited at its fundamental frequency ( $5 \mathrm{MHz}$ ) as well as at the $3 \mathrm{rd}, 5$ th, 7th, 9th, and 11th overtones, corresponding to $15,25,35,45$, and $55 \mathrm{MHz}$, respectively. A mass deposited onto the surface of the crystal causes a decrease in its resonant frequency. For rigidly attached layers, where the thickness of the layers is much lower than the thickness of the crystal itself, the resulting decrease in the resonant frequency is proportional to the mass of the 
Table 1. Characterization of pectins. $\bar{M}_{\mathrm{w}}$ and $\bar{M}_{\mathrm{n}}$ and $d\left(\bar{M}_{\mathrm{w}} / \bar{M}_{\mathrm{n}}\right)$ were obtained by SEC, while intrinsic viscosity $(\eta)$ and $\bar{M}_{\mathrm{v}}$ were obtained from viscosity measurements. $\mathrm{DE}_{\mathrm{PEC}}$ (degree of esterification) refers to the percentage of esterified groups in the pectin structure.

\begin{tabular}{lcccccc}
\hline & $\bar{M}_{\mathrm{w}}[\mathrm{KDa}]$ & $\bar{M}_{\mathrm{n}}[\mathrm{KDa}]$ & $d$ & $\eta\left[\mathrm{dl} \mathrm{g}{ }^{-1}\right]$ & $\bar{M}_{\mathrm{v}}[\mathrm{KDa}]$ & $\mathrm{DE}_{\mathrm{PEC}}[\%]$ \\
\hline $\mathrm{PEC}_{\mathrm{LM}}$ & 317 & 74 & 4.3 & 3.45 & 75 & 38 \\
$\mathrm{PEC}_{\mathrm{HM}}$ & 375 & 150 & 2.5 & 4.07 & 94 & 75 \\
\hline
\end{tabular}

deposited layer. In this case, the mass of the layer can be quantitatively interpreted using the Sauerbrey equation, relating $\Delta F$ and $\Delta m^{[39]}$ For viscoelastic materials the adsorbed layer does not fully couple to the oscillation of the crystal and therefore dampens the oscillation. The OCM-D response to viscoelastic layers is modeled using a Voigt model, that is a combination of a spring and dashpot to represent the elastic (storage) and inelastic (damping) behavior of a material, respectively. ${ }^{[40,41]}$

A Teflon liquid chamber with a volume of $2 \mathrm{~mL}$ was used in the experiments. Solutions used for the assembly and washing steps were alternatively introduced into the measurement chamber and were left in contact with the quartz crystal for 10 min for polysaccharide deposition. After each adsorption step, pure washing solution was poured into the chamber and left in contact with the crystal for $5 \mathrm{~min}$ in order to remove the unabsorbed molecules.

The data analysis was performed using the OCM Impedance Analysis software (KSV Instruments, version 3.11).

\subsubsection{LbL Deposition of CHI/PEC Multilayers}

Fresh polysaccharide solutions were prepared with a concentration of $0.5 \mathrm{mg} \mathrm{mL}^{-1}$ under agitation for $2 \mathrm{~h}$ at room temperature. This concentration value was set taking into account that it has been demonstrated in literature that to reach a surface charge reversion during linear polyion adsorption one needs a concentration greater than $10^{-5}$ $M$ and that a concentration range between 0.1 and $5 \mathrm{mg}$ $\mathrm{mL}^{-1}$ yields a similar bilayer thickness. ${ }^{[34]}$ Moreover, it has been demonstrated that a further decrease in polyion concentration (e.g., $0.01 \mathrm{mg} \mathrm{mL}^{-1}$ ) decreases the layer thickness of the adsorbed polyion and an increase in concentration (e.g., $20-30 \mathrm{mg} \mathrm{mL} \mathrm{m}^{-1}$ ) may result in the nonlinear (exponential) enlargement of the growth rate with adsorption steps. ${ }^{[42]}$ The $\mathrm{PEC}_{\mathrm{LM}}$ and $\mathrm{PEC}_{\mathrm{HM}}$ solutions were prepared in distilled water and the CHI one in $1.0 \%(\mathrm{v} / \mathrm{v})$ acetic acid solution. The $\mathrm{pH}$ of the polysaccharides solutions was adjusted to 4.0, 5.0, 6.0 by dropwise addition of $0.1 \mathrm{M} \mathrm{NaOH}$. The multilayers were deposited onto the surface of quartz crystals by the alternate deposition of $\mathrm{CHI}$ and $\mathrm{PEC}_{\mathrm{LM}}$ and $\mathrm{PEC}_{\mathrm{HM}}$. The polysaccharides were alternatively injected into the measurement chamber and allowed to equilibrate. The adsorption time was $10 \mathrm{~min}$ for both polysaccharides. This time of deposition was enough to reach saturation adsorption for both $\mathrm{CHI}$ and PEC. After each adsorption step, the crystal was washed with water ( $\mathrm{pH} 4.0,5.0,6.0$ ) for $5 \mathrm{~min}$ to remove the unbound material. Four $\mathrm{CHI} / \mathrm{PEC}_{\mathrm{LM}}$ and $\mathrm{CHI} / \mathrm{PEC}_{\mathrm{HM}}$ bilayers were deposited for each experiment and they were further named as $\left(\mathrm{CHI} / \mathrm{PEC}_{\mathrm{LM}}\right)_{4}$ and $\left(\mathrm{CHI} / \mathrm{PEC}_{\mathrm{HM}}\right)_{4}$. All experiments were carried out in triplicate.

\subsubsection{Mucoadhesion}

Mucoadhesion was studied by OCM-D by monitoring the interaction of the multilayers deposited onto the quartz crystal with a mucin solution at a concentration of $0.5 \mathrm{mg}$ $\mathrm{mL}^{-1}$ in $5 \times 10^{-3} \mathrm{M}$ phospate buffer at $\mathrm{pH} 6.8$ (oral $\mathrm{pH}$ ) and in acidified water solution at $\mathrm{pH} 1.5$ (gastrointestinal $\mathrm{pH}$ ). After the step-by-step deposition of four $\left(\mathrm{CHI} / \mathrm{PEC}_{\mathrm{LM}}\right)$ and $\left(\mathrm{CHI} / \mathrm{PEC}_{\mathrm{HM}}\right)$ bilayers, the mucin solution was injected into the measurement chamber and allowed to equilibrate for 30 min with continuous recording of the frequency change of the quartz crystal. The crystal was then washed by injecting a water solution, in the measurement chamber, at a $\mathrm{pH}$ equal to that used in the experiment (6.8 or 1.5) and allowed to equilibrate for $5 \mathrm{~min}$. All experiments were carried out in triplicate.

\subsubsection{NPCs Synthesis}

The NPCs were fabricated according to a well-established procedure. ${ }^{[4]}$ Namely, $10^{8} \mathrm{CaCO}_{3}$ or $\mathrm{MnCO}_{3}$ cores (diameter $5 \pm 2 \mu \mathrm{m}$ ) were covered by successively deposited layers of anionic PEC and cationic CHI. Specifically, PEC and CHI were used at a concentration of $0.5 \mathrm{mg} \mathrm{mL}^{-1}$. CHI was dissolved in $0.1 \mathrm{M}$ acetic acid, while pectin was dissolved in pure water; their $\mathrm{pH}$ was then adjusted to $\mathrm{pH} 5.0$ with $0.1 \mathrm{M} \mathrm{NaOH}$ and their adsorption time was $10 \mathrm{~min}$. Four bilayers were deposited onto the surface of the cores; after each step of deposition, the dispersion of covered cores was centrifuged at $3000 \mathrm{rpm}$ for $5 \mathrm{~min}$ and the precipitated covered cores were separated from the supernatant solution. The cores were washed three times in water at $\mathrm{pH} 5.0$ with successive centrifugation and separation steps and then dissolved by their dispersion in $0.5 \mathrm{M} \mathrm{EDTA} \mathrm{pH}$ 5.0 followed by three washings in water. All experiments were carried out in triplicate. 


\subsubsection{Optical and Scanning Electron Microscopy (SEM)}

SEM was used to provide information about the NPCshydrogel surface topography. SEM measurements were carried out by Zeiss Supra microscope on dried samples. The template removal and NPCs were visualized by optical microscopy (Olympus Invert Microscope).

\section{Results and Discussion}

As a first step, pectins were characterized by SEC (Table 1). Although the values cannot be considered as absolute values, as they are relative to pullulan standards, the comparison of the molecular weight values of the two pectins indicates that, the weight average molecular weight, $\bar{M}_{\mathrm{w}}$, and the numeral molecular weight average, $\bar{M}_{n}$, are lower for $\mathrm{PEC}_{\mathrm{LM}}$. The wider molar-mass dispersity and the peak shape in the chromatograms accounts a major amount of low molecular weight molecules for $\mathrm{PEC}_{\mathrm{LM}}$ than $\mathrm{PEC}_{\mathrm{HM}} \cdot{ }^{[43]}$ This result is consistent with a lower intrinsic viscosity and a lower $\bar{M}_{\mathrm{v}}$ for $\mathrm{PEC}_{\mathrm{LM}}$. The detailed characterization of the $\mathrm{PEC}_{\mathrm{HM}}$ is described in ref. ${ }^{[44]}$.

Different characteristics other than the molar mass, such as the charge and hydrophobic intramolecular associations, affect the dependence of the reduced viscosity as a function of concentration and salt content. In some conditions, these characteristics are interrelated. ${ }^{[45-48]}$ For pectin solutions, the reduced viscosity is decreasing with dilution. This result suggests that the polyelectrolyte effect is less relevant that the formation of entanglements and molecular aggregates by inter-chain interactions, in the salt containing solutions and concentrations (0.200-0.067 $\mathrm{mg} \mathrm{mL}^{-1}$ ) employed in this study.

The chitosan employed in this study was reported to have a molecular weight in the range 190-310 KDa, similar to the MW of pectins, and $77 \%$ of degree of deacetylation, thus bearing a large number of ionisable aminogroups. ${ }^{[49]}$ Water content was below $10 \%(2.2 \% \pm 0.2 \%$ for $\mathrm{PEC}_{\mathrm{HM}}, 6.7 \% \pm 2.4 \%$ for $\mathrm{PEC}_{\mathrm{LM}}, 7.8 \% \pm 1.2 \%$ for $\left.\mathrm{CHI}\right)$. The LbL self-assembly of PEC and CHI was monitored in real time by in situ OCM-D analysis, which combines the monitoring of resonant frequency $(\Delta f)$ and of the energy dissipation $(\Delta D)$, achieving information about the adsorbed mass (via $\Delta f / n, n=$ frequency overtone number) and the variation of the viscoelastic properties (via $\Delta D$ ) of the adsorbed multilayer. For rigid films the frequency changes deriving from the increasing of the layer mass are the same for all overtones. For viscoelastic layers $\Delta f$ versus time curves for different overtones do not coincide. This is evident in the kinetic OCM traces recorded during the buildup of all studied CHI/PEC multilayers (Figure 1). This was confirmed by monitoring the variation in the energy dissipation as a function of the number of deposited lay-

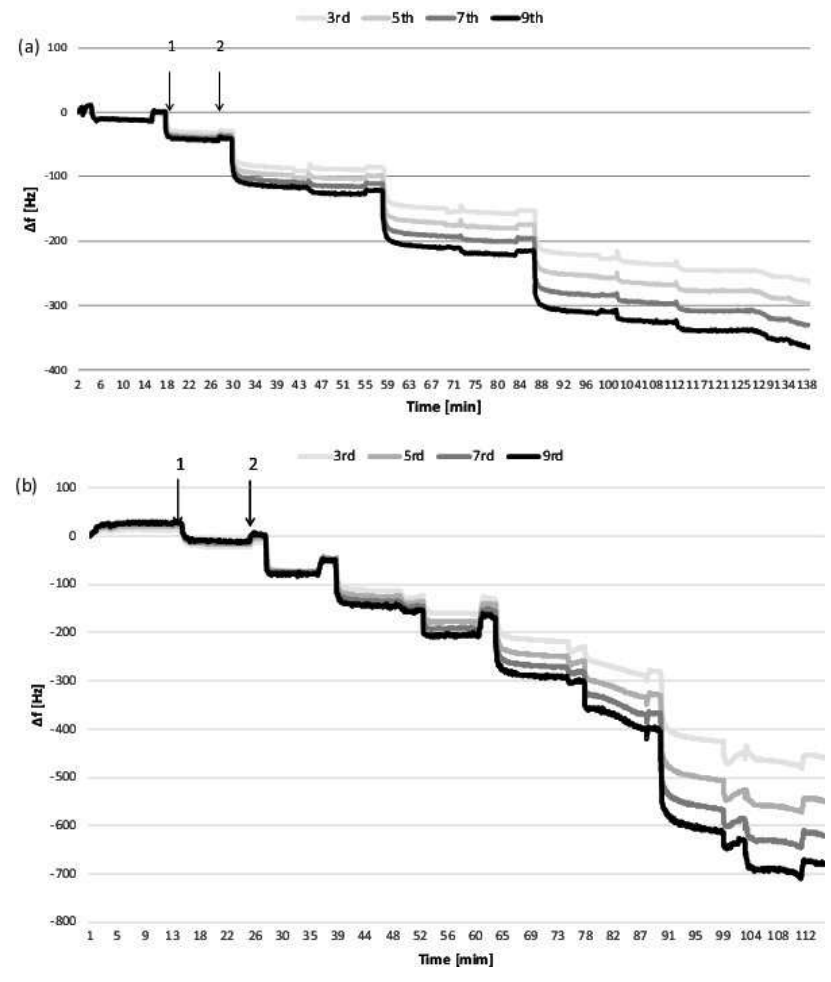

Figure 1. OCM-D results showing the in situ build-up of (CHI/PEC) $)_{4}$ films at $\mathrm{pH} 5$. Frequency changes are recorded as a function of time for $\mathrm{CHI} / \mathrm{PEC}_{\mathrm{LM}} \mathrm{A}$ ) and $\mathrm{CHI} / \mathrm{PEC}_{H M}$ B). Steps 1 and 2 represent chitosan and pectin deposition, respectively.

ers. If the adsorbed layer is rigid $\Delta D$ is close to 0 , if the adsorbed layer is not rigid $\Delta D>10^{-6} \cdot{ }^{[41]}$ For CHI/PEC multilayers, $\Delta D$ was found to be above $10^{-6}$ for all the tested assembly $\mathrm{pH}$ values, which indicates the deposition of viscoelastic multilayers. $\triangle \mathrm{D}$ for the multilayers $\left(\mathrm{CHI} / \mathrm{PEC}_{\mathrm{LM}}\right)_{4}$ and $\left(\mathrm{CHI} / \mathrm{PEC}_{\mathrm{LM}}\right)_{4}$ assembled at $\mathrm{pH} 5.0$ is reported in Figure 2. A more pronounced viscoelastic behavior for the multilayer $\left(\mathrm{CHI} / \mathrm{PEC}_{\mathrm{HM}}\right)_{4}$ than the one based on the use of $\mathrm{PEC}_{\mathrm{LM}}$ was observed. Since the multilayers exhibited viscoelastic behavior, the data were analyzed using the Voigt based model.

For clarity, changes in the measured data of the normalized fifth overtone $(f=15 \mathrm{MHz})$ are presented (Figure 1). The modeling was carried out using overtone frequencies of 25,35 , and $45 \mathrm{MHz}$.

The influences of the assembly $\mathrm{pH}(4.0,5.0$, and 6.0$)$ and of the degree of methylation of pectin $(38 \%, 75 \%)$ on the LbL deposition process were investigated. The evolution of surface coverage monitored during the deposition of 4 (CHI/PEC) bilayers at pH 5.0 is shown in Figure 3. Data analysis showed that the wet mass of $\left(\mathrm{CHI} / \mathrm{PEC}_{\mathrm{HM}}\right)$ was larger than that of $\left(\mathrm{CHI} / \mathrm{PEC}_{\mathrm{LM}}\right.$ ) (Figure 3). $\mathrm{PEC}_{\mathrm{HM}}$ formed more open, hydrated structures; whereas $\mathrm{PEC}_{\mathrm{LM}}$ formed more compact structures. The modeled thickness for the multilayers reflected this behavior, with the thinner mul- 
Table 2. CHI/PEC multilayer characteristics: surface coverage $(M / A)$ and thickness $(T)$ calculated with the Voight model for $\left(\mathrm{CHI} / \mathrm{PEC}_{\mathrm{LM}}\right)_{4}$ and $\left(\mathrm{CHI} / \mathrm{PEC}_{\mathrm{HM}}\right)_{4}$ as a function of the assembly $\mathrm{pH}$.

\begin{tabular}{lllllll}
\hline & $\mathrm{pH} 4.0$ & $\mathrm{pH} 5.0$ & $\mathrm{pH} 6.0$ & \\
\hline & $M / A\left[\mu \mathrm{g} \mathrm{cm}^{-2}\right]$ & $T[\mathrm{~nm}]$ & $M / A\left[\mu \mathrm{cm}^{-2}\right]$ & $T[\mathrm{~nm}]$ & $M / A\left[\mu \mathrm{cm}^{-2}\right]$ & $T[\mathrm{~nm}]$ \\
\hline$\left(\mathrm{CHI} / \mathrm{PEC}_{\mathrm{LM}}\right)_{4}$ & $1.89 \pm 0.09$ & $22 \pm 1.1$ & $2.2 \pm 0.13$ & $28 \pm 2$ & $2.67 \pm 0.2$ & $48 \pm 4$ \\
$(\mathrm{CHI} / \mathrm{PEC})_{4}$ & $4.2 \pm 0.23$ & $47 \pm 2$ & $4.26 \pm 0.25$ & $55 \pm 2.6$ & $6.86 \pm 0.44$ & $102 \pm 8$ \\
\hline
\end{tabular}

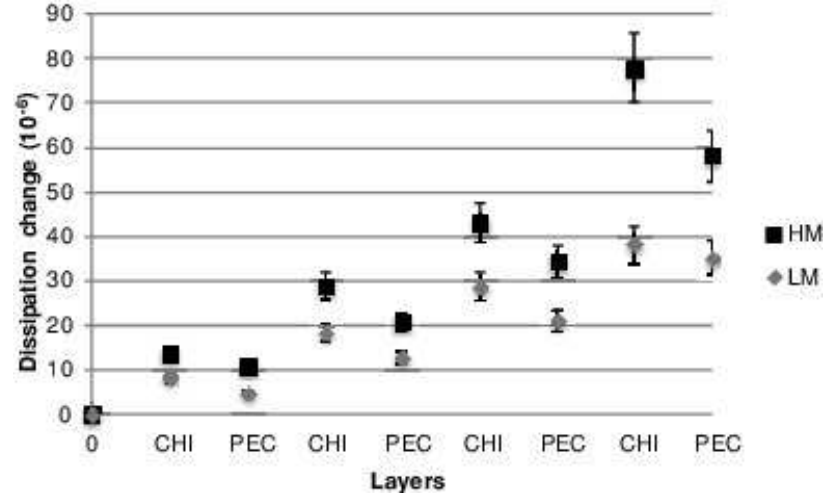

Figure 2. Dissipation changes recorded as a function of $L b L$ subsequently deposited chitosan and pectin layers for the multilayers $(\mathrm{CHI} / \mathrm{PEC})_{4}$ at $\mathrm{pH} 5$.

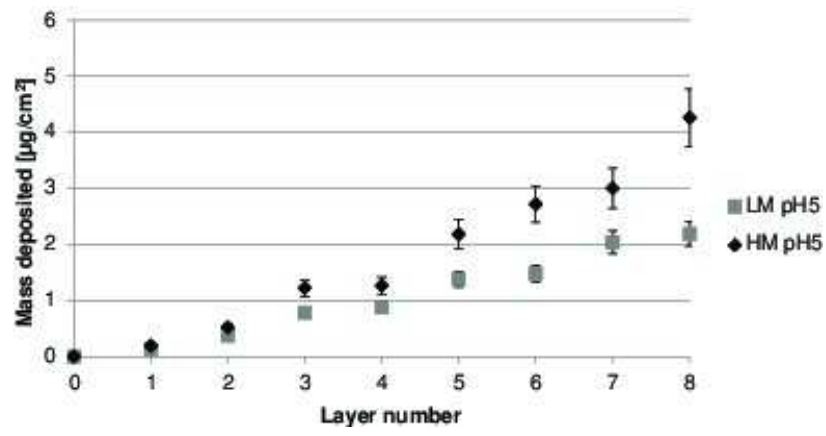

Figure 3. Plot of mass of polysaccharide deposited for chitosanpectin multilayered system at $\mathrm{pH} 5$ as a function of the number of layers calculated with the Voight model. The odd numbers correspond to deposited mass after the addition of chitosan and the even numbers concern pectin introduction.

tilayers recorded for $\mathrm{PEC}_{\mathrm{LM}}$. This behavior was observed at all three $\mathrm{pH}$ values as it is summarized in Table 2.

Since polyelectrolyte deposition is primarily controlled by electrostatic interactions, the degree of ionization of the charged molecule is of great importance. The thickness and the organization of these sequentially adsorbed layers are extremely sensitive to the $\mathrm{pH}$ of the solution, since the charge density and conformation of weak polyelectrolytes is influenced by the changes of $\mathrm{pH}$. At low $\mathrm{pH}$ values an increased charge density for chitosan is expected, resulting in a more compact and flat conformation.
When the $\mathrm{pH}$ increases and approaches the chitosan $\mathrm{pKa}$ 6.5 , the assembly of the multilayer is not mainly controlled by electrostatic interactions, but hydrogen bonds can also be formed. ${ }^{[28,50]}$ Moreover, at $\mathrm{pH}$ values closest to its $\mathrm{pKa}$, chitosan bears less charged groups to interact with pectin and, as a consequence, the film structure is more loosely packed and dissipates more energy ${ }^{[41]}$ This is in agreement with the different thickness values found at different $\mathrm{pH}$ values for both LM and HM pectins. Moreover, in Figure 2 it is possible to observe that the deposition of PEC leads to compaction of the structure, whereas chitosan has a more viscoelastic behavior. This can be explained taking into account that, when approaching its $\mathrm{pKa}$, chitosan has less charged groups. Consequently it behaves as a less rigid macromolecule, due to a decrease of electrostatic repulsions among charged groups and the deposition of successive pectin layer binds with the underneath chitosan, compacting the structure.

Polyelectrolyte deposition could also be affected by the molar-mass dispersity. The wider distribution for $\mathrm{PEC}_{\mathrm{LM}}$ can promote a more effective binding of the two polyelectrolites because of the presence of low molecular weight pectin macromolecules in the pectin solution.

Assembly at pH 5.0 was adopted for all subsequent experiments.

The mucoadhesive properties of CHI/PEC multilayers were studied in real time by OCM-D at $\mathrm{pHs}$ of the environment where the structure is going to be used. To this aim the LbL assembly of CHI and PEC, both LM and HM, was carried out on the surface of the quartz crystals at pH 5.0 and as final step the crystal was put in a contact with a solution of mucin. The multilayer/mucin interaction was characterized both at $\mathrm{pH} 6.8$ (oral mucosal surface) and at $\mathrm{pH} 1.5$ (gastrointestinal mucosal surface). The Voigt model was used to estimate the adsorbed mass due to the viscoelastic nature of the adsorbed film. The mucoadhesive properties for $\mathrm{PEC}_{\mathrm{LM}}$ and $\mathrm{PEC}_{\mathrm{HM}}$ showed a markedly different behavior.

As relates to the multilayers containing $\mathrm{PEC}_{\mathrm{LM}}$, upon injection in the measurement chamber of the mucin solution, a rapid decrease in frequency was observed reaching a constant value after $5 \mathrm{~min}$. After $30 \mathrm{~min}$, the mucin solution was rinsed from the chamber by a water solution at the same $\mathrm{pH}$ resulting in minor changes in frequency, 
indicating very little desorption of the layer. The deposited mass $\left(\mu \mathrm{g} \mathrm{cm}^{-2}\right.$ ) due to mucin adsorption onto $\left(\mathrm{CHI} / \mathrm{PEC}_{\mathrm{LM}}\right)_{4}$ multilayer onto the quartz crystal was found to be $0.16 \pm$ $0.01 \mu \mathrm{g} \mathrm{cm}^{-2}$ at $\mathrm{pH} 6.8$ and $4.72 \pm 0.09 \mu \mathrm{g} \mathrm{cm}^{-2}$ at $\mathrm{pH} 1.5$.

The stronger interaction at $\mathrm{pH} 1.5$ could be explained taking into account the pI of mucin and the $\mathrm{pKa}$ (3.2) of PEC. Mucin has an overall negative charge in basic and neutral solutions, which diminishes as the $\mathrm{pH}$ decreases below 4.0 as it gets closer to the isoelectric point (pI). In general, the pI of mucins range between 4.7 and 2.0, depending on the mucin's origin and preparation method. The pI of bovine submaxillary mucin (BSM), which was used in this work, has been determined to be about 3.0. ${ }^{[51]}$ Below this point, the mucin molecule becomes protonated and loses its negative charge. As relates to $\mathrm{PEC}$ at $\mathrm{pH}$ 1.5, which is below its $\mathrm{pKa}$, it is unionized. Thus the interaction is mediated by hydrogen bonding or other nonelectrostatic interactions. The LbL self-assembly process is governed primarily by electrostatic interactions. However, it has been demonstrated that hydrogen bonding, hydrophobic and other types of interactions are also involved in the process. ${ }^{[50]}$ As an example, Caruso and co-workers have successfully immobilized by LbL IgG molecules on the outer surface of a polyelectrolyte multilayers at a pH close to the IgG pI, which indicates an importance of hydrophobic interactions. ${ }^{[52]}$

At $\mathrm{pH}$ 6.8, $\mathrm{pH}$ higher than their $\mathrm{pKa}$, both pectin and mucin are negatively charged due to the ionization of carboxyl groups, in pectin, and sialic acid, in mucin resulting in an electrostatic repulsion and thus in decreased interaction.

As it relates to $\mathrm{PEC}_{\mathrm{HM}}$, the immediate and rapid interaction with mucin was followed by an immediate increase in frequency. Again, after 30 min the chamber was rinsed with water solution at the same $\mathrm{pH}$ as the mucin one. The frequency remained almost constant as in the $\mathrm{PEC}_{\mathrm{LM}}$ experiment. The increase in frequency could be related to the detachment of the last pectin layer at $\mathrm{pH}$ 6.8. This behavior was even more evident at acidic $\mathrm{pH}$ value were the exposition to a mucin solution at $\mathrm{pH} 1.5$ resulted in the detachment of a mass corresponding to the last (CHI/PEC) bilayer. This could be explained as a consequence of the fact that the interaction in this case is based on hydrogen bonding, which is stronger than the electrostatic interaction between positively charged mucin and uncharged pectin. This finally results in the detachment of the weakly bound polysaccharide layers that are weakly associated with the underlying layers. $\mathrm{PEC}_{\mathrm{HM}}$ has a lowest charge density and a highest hydrophobicity compared to $\mathrm{PEC}_{\mathrm{LM}}$. The differences observed for $\mathrm{PEC}_{\mathrm{LM}}$ and $\mathrm{PEC}_{\mathrm{HM}}$ could be explained taking into account the different polymer conformations in the multilayer and the compactness of the adsorbed layer. $\mathrm{PEC}_{\mathrm{HM}}$ may form loops and has a more branched structure. Moreover, $\mathrm{PEC}_{\mathrm{HM}}$ has a lower charge density and a higher hydrophobicity compared to the $\mathrm{PEC}_{\mathrm{LM}}$. This
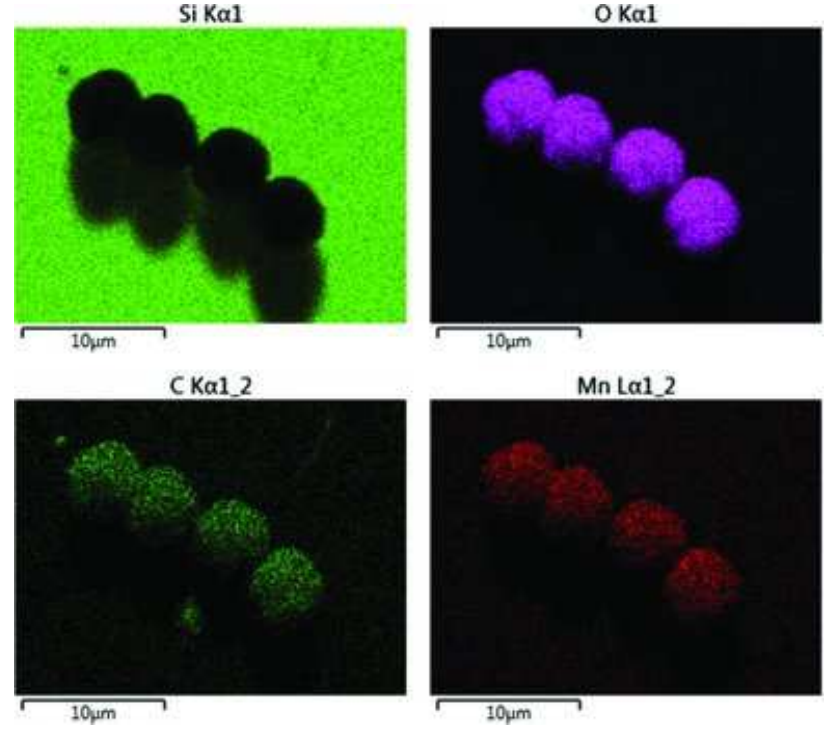

Figure 4. EDS map of $\mathrm{MnCO}_{3}$ covered templates. Location of paint pigment containing iron is shown by green dot pattern.

could result from a weaker interaction with chitosan, on the one hand, and from the lower electrostatic repulsion and higher degree of hydrophobic interaction with mucin, on the other hand.

For NPCs synthesis, $\mathrm{MnCO}_{3}$ and $\mathrm{CaCO}_{3}$ microparticles, having a diameter of $5 \pm 2 \mu \mathrm{m}$, were used. Namely, CHI and $\mathrm{PEC}_{\mathrm{LM}}$ were subsequently adsorbed onto the particle surface using the LbL deposition technique at $\mathrm{pH}$ 5.0. $\mathrm{PEC}_{\mathrm{LM}}$ was chosen for the synthesis of the NPCs in a view of obtaining a more compact multilayered shell for the subsequent loading of active molecules in the NPC hollow void. Four bilayers were deposited and chitosan was the first layer adsorbed onto the templates. Two methods to obtain hollow capsules were compared.

The first method is based on the use of $\mathrm{MnCO}_{3}$ covered templates which were dissolved by the addition of $\mathrm{HCl} 0.1$ $\mathrm{M}$ to reach $\mathrm{pH} 4.0$, when the shell should have a slightly opened conformation, and then by the addition of EDTA $0.1 \mathrm{M} \mathrm{pH}$ 7.0. Energy Dispersive X-ray Spectroscopy (EDS) image of the covered templates is shown in Figure 4 . The sizes and the elements composition correspond well to the covered templates. The dissolution process was monitored by optical microscopy. The dissolution was found to be difficult as all attempts to obtain a dispersion of just hollow NPCs, without the presence of templates, also resulted in the dissolution of most of the multilayered shells.

In order to clarify this observation, the dissolution of both $\mathrm{MnCO}_{3}$ either $\mathrm{CaCO}_{3}$ cores was carried out only by subsequent additions of $\mathrm{HCl} 0.1 \mathrm{M}$. In this case, the complete removal of the cores resulted in the complete dissolution of the multilayered shells. 

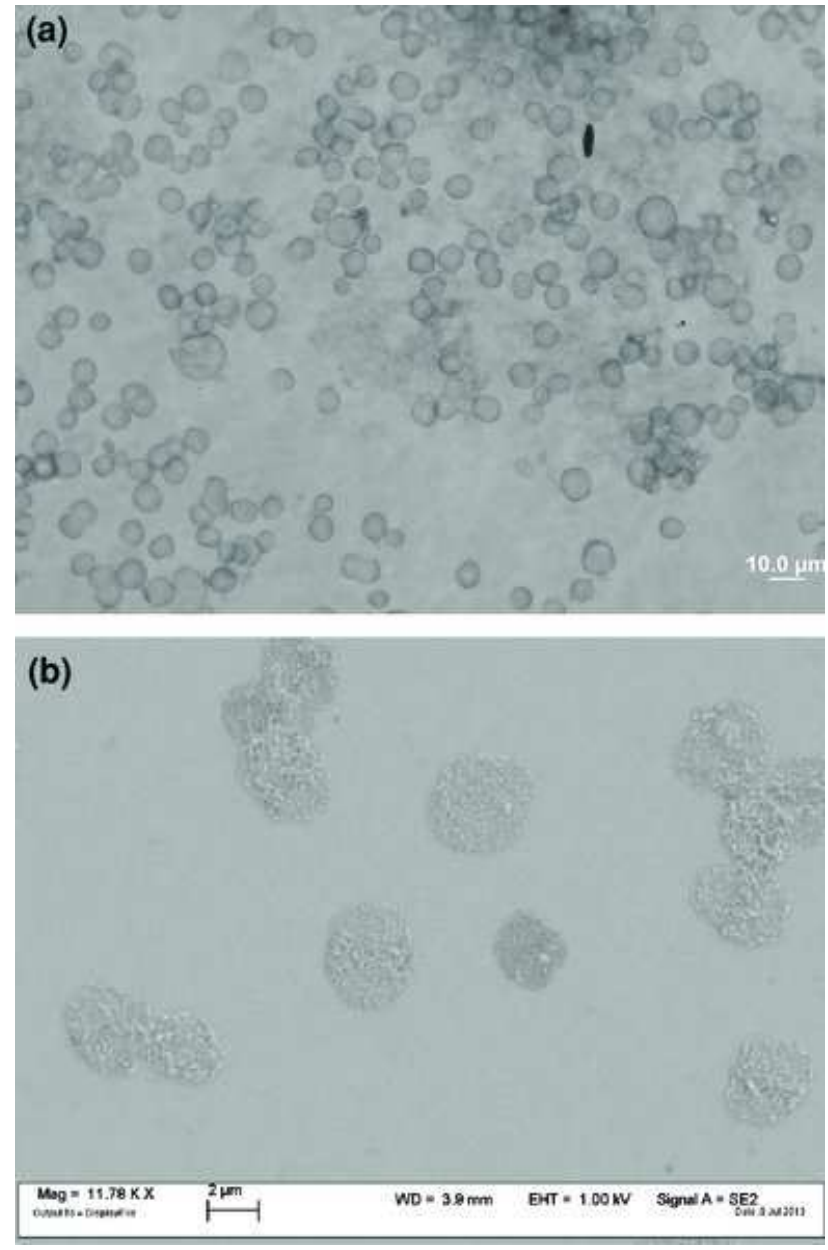

Figure 5. A) Optical and B) SEM microscopies images of $\left(\mathrm{CHI} / \mathrm{PEC}_{\mathrm{LM}}\right)_{4} \mathrm{NPCS}$.

This behavior can be explained taking into account the low $\mathrm{pH}$ ( $\mathrm{pH}$ 3.0) required to dissolve the cores, which is below the PEC $\mathrm{PKa}$ (3.5), where the protonation of the anionic group can weaken the electrostatic interactions.

The second method is based on the obtained hollow NPCs by dissolving $\mathrm{CaCO}_{3}$ in EDTA $0.1 \mathrm{M}$ at $\mathrm{pH}$ 5.0. In order to visualize better the obtained capsules by optical microscopy, they were stained by trypan blue (Figure $5 \mathrm{a}$ ). Figure $5 b$ reports a SEM image of dried NPCs. The NPCs samples were then stored in pure water at $4{ }^{\circ} \mathrm{C}$ for up to six months and the samples were periodically visualized by optical microscopy to assess their storage stability. The samples were found to be stable during the observation period since no morphological modification was observed. Further testing on stability, such as in simulated physiological fluids, will be investigated in future work.

These data suggest that water affinity to the hydrophilic backbones of each polyelectrolyte layer do not promote NCPs disruption, suggesting the formation of a stable interaction among the layers. The study of NCPs need to be expanded to different model media.

Future work will be focused on the characterization of the permeability properties of the NPCs to evaluate their potentiality as local drug delivery system, according to the mechanism previously reported for drug loading in LbL polyelectrolyte microcapsules. ${ }^{[2]}$

\section{Conclusions}

Multilayers and nanostructured capsules of the polysaccharides chitosan and pectin were successfully assembled by the LbL technique. OCM-D was used to characterize the assembly of the two polysaccharides in real time. The features of multilayers assembled using pectins with different amounts of charged groups and different assembly pHs were found to be strongly dependent on the intrinsic features of the pectin molecules and on the adopted assembly conditions. Multilayers assembled using HM pectin showed a more pronounced viscoelastic behavior and a higher thickness at all the assembly pHs, while multilayers based on $\mathrm{PEC}_{\mathrm{LM}}$ were found to be more compact and were thus selected for the subsequent synthesis of NPCs. $\mathrm{PEC}_{\mathrm{LM}}$ was found to stably interact with mucin at $\mathrm{pH} 1.5$ and 6.8 in terms of adsorbed mass. NPCs obtained by the alternate assembly of chitosan and LM pectin were found to be stable.

The results point out that it is possible to fabricate NPCs based on chitosan and pectin polysaccharides. Such systems can be considered as promising systems for applications in the biomedical field, in mucosal drug delivery and in food industry. In addition, the possibility of the loading of similar capsules with drugs with their successive release has already been demonstrated..$^{[9]}$

Acknowledgements: This work was funded by the Italian Ministry of University and Research (MIUR) through the Project PRIN "NANO Molecular Technologies for Drug delivery (prot. 2010FPTBSH_009)." The work is partially performed according to the Russian Government Program of Competitive Growth of Kazan Federal University.

Received: November 28, 2014; Revised: February 21, 2015; 
[1] K. Ariga, Y. M. Lvov, K. Kawakami, Q. Ji, J. P. Hill, Adv. Drug Deliv. Rev. 2011, 63, 762.

[2] L. Pastorino, S. Erokhina, V. Erokhin, Curr. Org. Chem. 2013, 17, 58.

[3] B. G. De Geest, S. De Koker, G. B. Sukhorukov, O. Kreft, W. J. Parak, A. G. Skirtach, J. Demeester, S. C. De Smedt, W. E. Hennink, Soft Matter 2009, 5, 282.

[4] G. B. Sukhorukov, E. Donath, H. Lichtenfeld, E. Knippel, M. Knippel, A. Budde, H. Möhwald, Colloids Surf., A 1998, 137, 253.

[5] E. Donath, G. B. Sukhorukov, F. Caruso, S. A. Davis, H. Möhwald, Angew. Chem. Int. Ed. 1998, 37, 2201.

[6] A. Antipov, G. B. Sukhorukov, S. Leporatti, I. L. Radtchenko, E. Donath, H. Möhwald, Colloids Surf., A 2002, 198, 535

[7] A. A. Antipov, G. B. Sukhorukov, Adv. Colloid Interface Sci. 2004, 111, 49.

[8] G. Skirtach, A. A. Antipov, D. G. Shchukin, G. B. Sukhorukov, Langmuir 2004, 20, 6988.

[9] L. Pastorino, S. Erokhina, F. Caneva-Soumetz, C. Ruggiero, J. Nanosci. Nanotechnol. 2009, 9, 6753.

[10] L. Pastorino, S. Erokhina, F. C. Soumetz, P. Bianchini, O. Konovalov, A. Diaspro, C. Ruggiero, V. Erokhin, J. Colloid Interface Sci. 2011, 357, 56.

[11] S. Erokhina, L. Benassi, P. Bianchini, A. Diaspro, V. Erokhin, M. P. Fontana, J. Am. Chem. Soc. 2009, 131, 9800.

[12] S. Dumitriu, in Polymeric Biomaterials, Revised and Expanded (Ed: S. Dimitriu), Marcel Dekker, New York 2001, p. I/1.

[13] S. Mizrahy, D. Peer, Chem. Soc. Rev. 2012, 41, 2623.

[14] M. Paini, B. Aliakbarian, A. A. Casazza, P. Perego, C. Ruggiero, L. Pastorino, Mater. Sci. Eng., C 2015, 46, 374.

[15] T. R. R. S. Rahamatullah Shaikh, M. J. Garland, A. D. Woolfson, R. F. Donnelly, J. Pharm. Bioallied Sci. 2011, 3, 89.

[16] J. D. Smart, Adv. Drug Deliv. Rev. 2005, 57, 1556.

[17] V. V Khutoryanskiy, Macromol. Biosci. 2011, 11, 748.

[18] M. C. Koetting, N. A. Peppas, Int. J. Pharm. 2014, 471, 83.

[19] A. Bernkop-Schnürch, S. Dünnhaupt, Eur. J. Pharm. Biopharm. 2012, 81, 463.

[20] M. Rinaudo, Prog. Polym. Sci. 2006, 31, 603.

[21] W. G. T. Willats, L. McCartney, W. Mackie, J. P. Knox, Plant Mol. Biol. 2001, 47, 9.

[22] F. Munarin, M. C. Tanzi, P. Petrini, Int. J. Biol. Macromol. 2012, 51, 681 .

[23] F. Munarin, S. G. Guerreiro, M. A. Grellier, M. C. Tanzi, M. A. Barbosa, P. Petrini, P. L. Granja, Biomacromolecules 2011, 12, 568

[24] E Secchi, F Munarin, MD Alaimo, S Bosisio, S Buzzaccaro, G Ciccarella, V Vergaro, P Petrini, R Piazza, J. Phys.: Condens. Matter 2014, 26, 4106.

[25] H. R. Moreira, F. Munarin, R. Gentilini, L. Visai, P. L. Granja, M. C. Tanzi, P. Petrini, Carbohydr. Polym. 2014, 103, 339.

[26] F. Bigucci, B. Luppi, T. Cerchiara, M. Sorrenti, G. Bettinetti, L. Rodriguez, V. Zecchi, Eur. J. Pharm. Sci. 2008, 35, 435.

[27] N. Habibi, L. Pastorino, C. Ruggiero, Mater. Sci. Eng., C 2014, 35,15 .

[28] Y. Lvov, in Encyclopedia of Surface and Colloid Science (Ed: A. Hubbard), Marcel Dekker, New York 2002, p. 321.

[29] H. Ai, S. A. Jones, M. M. de Villiers, Y. M. Lvov, J. Controlled Release 2003, 86, 59.

[30] X. Qiu, S. Leporatti, E. Donath, H. Möhwald, Langmuir 2001, 17, 5375

[31] O. P. Tiourina, G. B. Sukhorukov, Int. J. Pharm. 2002, 242, 155.

[32] H. Anger, G. Berth, Carbohydr. Polym. 1986, 6, 193.

[33] F. Munarin, P. Petrini, M. C. Tanzi, M. A. Barbosa, P. L. Granja, Soft Matter 2012, 8, 4731.

[34] M. Sano, Y. Lvov, T. Kunitake, Ann. Rev. Mater. Sci. 1996, 26, 153.
[35] Y. Lvov, K. Ariga, T. Kunitake, Colloids Surf., A 1999, 146, 337.

[36] F. Caruso, K. Niikura, N. Furlong, Y. Okahata, Langmuir 1997, 13, 3427.

[37] M. V. Voinova, M. Rodahl, M. Jonson, B. Kasemo, Phys. Scr. 1999, 59, 391.

[38] K. A. Marx, Biomacromolecules 2003, 4, 1099.

[39] G. Z. Sauerbrey, Physica A 1959, 155, 206.

[40] P. Kujawa, G. Schmauch, T. Viitala, A. Badia, F. M. Winnik, Biomacromolecules 2007, 8, 3169.

[41] T. Viitala, J. T. Hautala, J. Vuorinen, S. K. Wiedmer, Langmuir 2007, 23, 609.

[42] D. Yoo, J. Lee, M. Rubner, Mater. Res. Symp. Proc. 1996, 413, 395.

[43] H. H. Shuai, C. Y. Yang, H. I. C. Harn, R. L. York, T. C. Liao, W. S. Chen, J. A. Yeh, C. M. Cheng, Chem. Sci. 2013, 4, 3058.

[44] I. Fraeye, T. Duvetter, I. Verlent, D. N. Sila, M. Hendrickx, A. Van Loey, Innovative Food Sci. Emerging Technol. 2007, 8, 93.

[45] S. H. Yoo, M. L. Fishman, A. T. Hotchkiss, Jr., H. G. Lee, Food Hydrocolloids 2006, 20, 62.

[46] L. Guo, K. C. Tam, R. D. Jenkins, Macromol. Chem. Phys. 1998, 199, 1175.

[47] M. V. Badiger, N. R. Gupta, J. Eckelt, B. A. Wolf, Macromol. Chem. Phys. 2008, 209, 2087.

[48] M. Rinaudo, Macromol. Biosci. 2006, 6, 590.

[49] C. Gartner, B. L. López, L. Sierra, R. Graf, H. W. Spiess, M. Gaborieau, Biomacromolecules 2011, 12, 1380.

[50] Y. Lvov, K. Ariga, I. Ichinose, T. Kunitake, J. Am. Chem. Soc. 1995, 117, 6117

[51] I. A. Bushnak, F. H. Labeed, R. P. Sear, J. L. Keddie, Biofouling 2010, 26, 387.

[52] F. Caruso, N. Furlong, K. Ariga, I. Ichinose, T. Kunitake, Langmuir 1998, 14, 4559.

[53] G. Decher, Science 1997, 277, 1232. 